TITLE:

\title{
Control of particle charge by atmospheric pressure plasma jet (APPJ): A review
}

$\operatorname{AUTHOR}(\mathrm{S}):$

Matsusaka, Shuji

\section{CITATION:}

Matsusaka, Shuji. Control of particle charge by atmospheric pressure plasma jet (APPJ): A review. Advanced Powder Technology 2019, 30(12): 2851-2858

ISSUE DATE:

2019-12

URL:

http://hdl.handle.net/2433/244839

\section{RIGHT:}

(c) 2019. This manuscript version is made available under the CC-BY-NC-ND 4.0 license

http://creativecommons.org/licenses/by-nc-nd/4.0/; The full-text file will be made open to the public on 1 December 2021 in accordance with publisher's 'Terms and Conditions for Self-Archiving'.; This is not the published version. Please cite only the published version; この論文は出版社版でありません。引用の際には出版社版をご確認ご利用ください。 
Manuscript for Advanced Powder Technology

\title{
Control of particle charge by atmospheric pressure plasma jet (APPJ): A review
}

Shuji Matsusaka

Department of Chemical Engineering, Kyoto University, Kyoto 615-8510, Japan

E-mail address:matsu@cheme.kyoto-u.ac.jp

\begin{abstract}
Atmospheric pressure plasma jets (APPJs) have more advantages regarding flexibility of operation than low pressure plasmas. Because the ions and/or electrons in the APPJ can be arbitrarily extracted to a gas-phase space by changing the DC bias voltage and efficiently deposited onto particle surfaces in an external electric field, this operating technique can be applied towards controlling particle charge. Several methods to control the particle charge using an APPJ system have already been reported. This article summarizes the specifications and operations of these systems, their mechanisms of charge transfer, and methods for particle charging, based on previously reported work. The methods are categorized into three groups, i.e., direct charging of particles, direct charging of a powder bed, and indirect charging of particles, and the corresponding experimental setups, procedures, results, and discussions are presented.
\end{abstract}

Keywords:

Particle; Powder bed; Electrostatic charge control; Atmospheric pressure plasma jet (APPJ) 


\section{Contents}

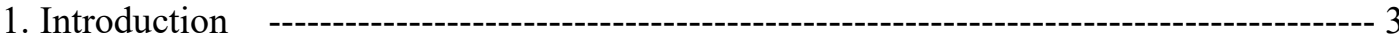

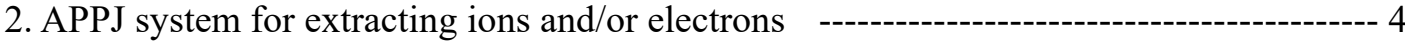

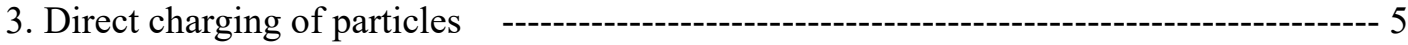

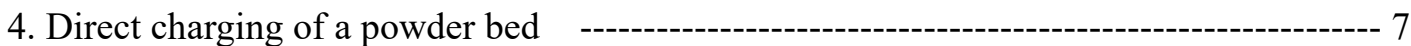

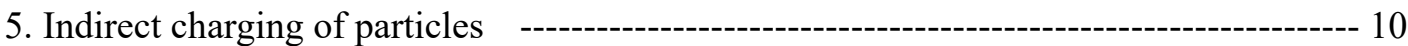

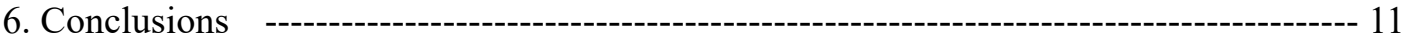

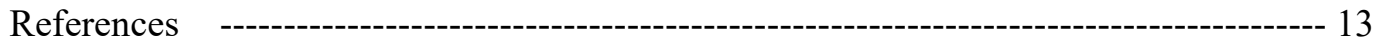




\section{Introduction}

Plasma is a state of matter in which gas molecules are dissociated into positive and negative ions and electrons. Although plasmas have been used in various processes, their physical and chemical characteristics depend on the operating conditions. Some plasmas that have high temperatures and are in thermal equilibrium are called hot plasmas or thermal plasmas. Other plasmas that have ambient temperature and are in non-thermal equilibrium are called cold plasmas or non-thermal plasmas.

The cold plasmas are easily generated under vacuum and have excellent application for effects such as surface cleaning, surface treatment, etching, and film formation; however, a vacuum system is essential in this method, and a pressure switching device is required for continuous operation $[1,2]$. When using rare gases such as helium or argon, cold plasmas can be easily generated even under atmospheric pressure. These are called cold atmospheric pressure plasma jets or simply atmospheric pressure plasma jets (APPJs). Since this system has more advantages concerning the flexibility of operation than low pressure plasmas, the development of various applications, such as surface modification [3], microbial decontamination [4], and medical treatment [5], has been enabled.

By applying alternating current (AC) voltage, an APPJ with a weak bluish light is generated in free space. In fact, plasma bullets with higher velocities than gas are formed discretely by cycling the applied AC voltage [6-8]. Analyses of APPJs injected into ambient air have been presented, and the research on the formation mechanism of the APPJ is progressing rapidly [9-12]. However, there are few studies regarding the electrostatic effects of ions and electrons in APPJs on the surroundings.

In general, charged particles experience electrostatic forces [13-15]. In gas-solid pipe flows, charged particles are deposited on the inner walls and form particle layers [16], adversely affecting the flow. However, electrostatic charges and forces can be applied to the measurement of particles [17-19] and control of particle positions [20]. For electrostatic applications and analysis of phenomena related to particle charging, evaluation of the particle 
charging properties [21-23] and control of particle charges are required [24,25]. APPJ contains many ions and electrons. When these charges are arbitrarily extracted to a gas-phase space and efficiently deposited onto the particle surfaces, the control of particle charges can be achieved.

The APPJ systems suitable for controlling particle charges and their relevant methods have already been studied [26-28]. This article summarizes the specifications and operations of these APPJ systems, their mechanisms of charge transfer, and methods for particle charging, based on previously reported work.

\section{APPJ system for extracting ions and/or electrons [26]}

\subsection{System and structure}

Fig. 1 shows an APPJ system, which consists of a mass flow controller for helium, a function generator to produce AC and DC voltages, an amplifier, and an APPJ nozzle. A cylindrical electrode was placed in a dielectric tube of 8-mm inner diameter and made of quartz glass. No grounding electrode was used in this system because it distorts the electric field generated by the APPJ and decreases the efficiency of charge extraction.

\subsection{Extraction of ions and/or electrons in APPJ to gas-phase space}

In this system, the $\mathrm{AC}$ voltage was set at $5 \mathrm{kV}$ in peak and $6 \mathrm{kHz}$, and the $\mathrm{DC}$ bias voltage was used to extract ions and/or electrons. To evaluate the quantities of the generated charges and their polarities, electric currents were detected around the APPJ by a sensor probe of diameter $2 \mathrm{~mm}$ and length $8 \mathrm{~mm}$. The APPJ was influenced by ambient conditions, particularly relative humidity $\varphi$ [29], the value of which was also measured as a reference.

Fig. 2 shows the effect of the DC bias voltage $V_{\mathrm{b}}$ on the detected electric current. The current varied widely from negative to positive values. This result indicates that the DC bias voltage can control the charge generated by the APPJ. The current was positive at zero bias voltage, meaning that a greater number of positive ions tended to remain in the gas-phase space 
compared to electrons.

Fig. 3 shows the photographs of APPJs generated at different flow rates of helium gas. The length of the APPJ was $20 \mathrm{~mm}$ at 1 standard liter per minute (SLM) and was $80 \mathrm{~mm}$ at 10 SLM. Although the length increased with an increase in the flow rate, excessive supply of helium gas should be avoided because a large flow rate could disturb the stable state of the gasphase space.

Fig. 4 shows the two-dimensional distributions of the electric currents detected by the sensor probe, which indicate the distributions of the space charge densities around the APPJ. As the flow rate of helium gas increases, the space charge density increases along the center axis of the APPJ but decreases with an increase in the distance from the center axis.

\section{Direct charging of particles [26]}

\subsection{Experimental setup and procedure}

Fig. 5 shows a schematic of the experimental setup for directly charging particles by the APPJ. The particles were continuously fed by a vibratory feeder for 2 min and were incident on a dielectric (insulating) plate that was placed over a metal plate. The APPJ was generated in the horizontal direction at a certain height, and two different experiments were conducted. The first experiment involved passing the particles through the APPJ, whereas the second one involved not passing the particles through the jet; i.e., first, the particles fell on the dielectric plate for $2 \mathrm{~min}$, and then the charges generated by the APPJ was irradiated for $2 \mathrm{~min}$. The charge of the particles was measured by a Faraday cup electrometer. The operating parameters were: i) APPJ nozzle height $h$ (i.e., vertical distance from the surface of the dielectric plate), ii) DC bias voltage $V_{\mathrm{b}}$, iii) external electric voltage $V_{\mathrm{ex}}$, and iv) helium flow rate $Q$. The properties of all the powders used are listed in Table 1.

\subsection{Experimental results and discussion}

Fig. 6 shows the effect of the vertical distance between the APPJ nozzle and the dielectric 
plate on the surface charge densities of the particles. As a DC bias voltage of $+5 \mathrm{kV}$ was applied to the electrode of the nozzle, positive charges were extracted to the gas-phase space and directly deposited on the particles (manganese ferrite). The charges on the particles passing through the APPJ (solid line) were greater than those not passing through it (broken line); however, the general trends for decreasing particle charge with increase in the vertical distance were for both. Therefore, the process where the particles pass through the APPJ is not essential for particle charging; rather, the effect of the vertical distance is considered significant. As the duration of the APPJ irradiation was sufficiently large $(2 \mathrm{~min})$, the surface charge density of the particles was in an equilibrium state. Since the dielectric plate was placed on the grounded metal plate, positive charges generated by the APPJ moved downward along the electric field lines and were deposited on the particles on the dielectric plate. When the vertical distance is short, the electric field strength is high; consequently, the particle charging based on the electric field is enhanced. Since the particles passing through the APPJ are exposed to a strong electric field for a short period of time, the efficiency of the particle charge can be somewhat large.

Fig. 7 shows the effect of DC bias voltage on the surface charge densities of the particles. The surface charge density varied from negative to positive as the DC bias voltage was correspondingly varied from negative to positive. The DC bias voltage affects the polarity and charge density in the gas-phase space, which also affects the electric field; subsequently, the particles are charged by the electric field. Thus, the trend shown in Fig. 6 is also seen in Fig. 7, i.e., the charge on the particles passing through the APPJ (solid line) was greater than on those not passing through it (broken line).

Fig. 8 shows the results for particles of different materials (see Table 1). These experiments were conducted without passing the particles through the APPJ. The relationships between the surface charge densities and DC bias voltages are similar, meaning that the charges generated by the APPJ can control particle charge irrespective of the physical properties of the particles themselves.

In principle, particle charging can be controlled by the external electric field. To confirm 
the applicability of this charge control, experiments were conducted. Different external voltages were applied to the metal plate under the dielectric plate, and the APPJ was generated for $2 \mathrm{~min}$.

Fig. 9 shows the effect of the external voltage on particle charging. The particle surface charge densities varied widely owing to the change in the external voltage applied to the metal plate as well as the DC bias voltage applied to the electrode in the APPJ nozzle. The results indicate that this method is excellent for flexibility and extensibility of controlling particle charge.

Fig. 10 shows the effect of helium flow rate on particle charging. These experiments were conducted at a DC bias voltage of +5 and $-5 \mathrm{kV}$. The absolute value of the particle surface charge density increases with an increase in the flow rate when helium gas is applied at less than 1 SLM; however, the value is almost constant at higher flow rates. As shown in Fig. 4, the space charge density increases along the center axis of the APPJ but decreases with an increase in the distance from this axis. Therefore, an excessively high flow rate of helium gas is not effective for particle charging. Furthermore, the effect of the irradiation time of the APPJ on particle charging is examined. The results show that the particles are charged sufficiently even when irradiated only for a few seconds.

\section{Direct charging of a powder bed [27]}

\subsection{Experimental setup and procedure}

Fig. 11 shows a schematic of the experimental setup for directly charging a powder bed by the APPJ. A suitable powder was packed in an open box with a square base of area $50 \times 50$ $\mathrm{mm}^{2}$ and made of acrylic resin, which was placed over a grounded metal plate. The thickness of each powder bed was less than $7 \mathrm{~mm}$. The APPJ was provided at a height of $40 \mathrm{~mm}$ from the bottom of the box. The operating conditions were as follows: AC voltage applied to the electrode in the APPJ nozzle was set at $5 \mathrm{kV}$ in peak and $6 \mathrm{kHz}$, and the flow rate of helium gas was 1 SLM. The powders used were polytetrafluoroethylene (PTFE) with a high resistivity 
and manganese ferrite with a low resistivity (see Table 1).

\subsection{Experimental results and discussion}

Fig. 12 shows the efficiency of particle charging normalized by the maximum measurement for PTFE. The efficiency is almost 1 for an area of $25 \times 25 \mathrm{~mm}^{2}$ but decreases with an increase in the horizontal distance from the center of the APPJ. For example, it reduced to $85 \%$ at a position $50 \mathrm{~mm}$ away from the center; consequently, the area for which the efficiency exceeds $85 \%$ is approximately $0.1 \times 0.1 \mathrm{~m}^{2}$. When a large area needs to be charged, a scanning device will be required.

Next, to obtain detailed information on particle charging, experiments were conducted using powder beds of thickness $2 \mathrm{~mm}$ each. After irradiation of the charges generated by the APPJ, the particles were collected in a cylindrical filter in a Faraday cup with a suction system. The upper layer particles were easily removed from the box; in contrast, the lower layer particles were hard to remove. This was because the lower layer of particles adhered to the bottom of the box owing to stronger electrostatic forces; thus, the upper and lower layer particles were separately collected using the differences in their adhesion forces.

Fig. 13 shows the specific charges of the upper layer, lower layer, and all particles collected after irradiation of the APPJ. As a reference, the surface charge densities of the particles are shown on the right-side axis of the figure. The particles acquired negative charges because of a negative DC bias voltage $(-5 \mathrm{kV})$. The charge of the upper layer particles reached an equilibrium value $(-18 \mu \mathrm{C} / \mathrm{kg})$ in a few seconds, whereas that of the lower layer of particles varied gradually from -42 to $-46 \mu \mathrm{C} / \mathrm{kg}$ in $1 \mathrm{~min}$. This difference in time dependence is significant. The total charge of all the particles varied gradually from -25 to $-38 \mu \mathrm{C} / \mathrm{kg}$. This value depended on the number of particles as well as their charges. Here, it is worth noting that although the charges were supplied on the surfaces of the powder beds, the absolute value of the charge of the lower layer of particles is larger than that on the upper layer of particles. This observation is explained as follows: i) the charges of the upper layer particles transfer to the 
lower layer particles through the surfaces of the particles, according to the existence of the electric field; ii) since the surfaces have a certain electrical resistance, it takes time to transfer these charges; iii) the charges transferred to the lower layer of particles cannot pass through the acrylic box; thus, the charges accumulate until the electric field is cancelled out by the transferred charges.

Fig. 14 shows the effect of the thickness of the powder bed on the specific charges of the upper layer, lower layer, and all particles. This experiment was conducted for 1 min of irradiation of the APPJ generated at $+5 \mathrm{kV}$ DC voltage. Although PTFE particles tend to acquire negative charges by contact with other materials because of the difference in the work function, the APPJ can easily supply positive charges as well as negative charges to the particles. Similar to the results shown in Fig. 13, the absolute value of the charge of the lower layer of particles is larger than that of the upper layer of particles. In addition, this result indicates that the specific charge decreases with an increase in the thickness of the powder bed. Furthermore, the decreasing rate of charge for the total particles changes at a thickness of approximately $2 \mathrm{~mm}$. When the powder bed becomes thick, the total charge of all the particles approaches that of the upper layer of particles, meaning that the mass ratio of the upper layer of particles increases with an increase in the thickness of the powder bed.

Fig. 15 shows the effect of the thickness of the powder bed on the mass ratio of the upper layer of particles to the total particles. The mass ratio of the upper layer of particles is approximately 0.4 when the thickness of the layer is less than $2 \mathrm{~mm}$. As the thickness increases, the mass ratio increases. Therefore, the thicker the powder bed, the more difficult it is to transfer the charges to the bottom layer.

Fig. 16 shows the effect of the thickness of the manganese ferrite powder bed, whose resistivity is rather low, on the specific charges of the upper layer, lower layer, and all particles. Although the upper layer of particles was almost uncharged, the lower layer of particles was highly charged. These particle charges are much higher than those in the case of PTFE (see Fig. 14). The specific charge of the total particles is close to that of the upper layer of particles, 
meaning that the mass ratio of the upper layer of particles is very high. For a $1 \mathrm{~mm}$ thick bed, the mass ratio was $90 \%$, and for a $4 \mathrm{~mm}$ thick bed, it was $98 \%$. This result indicates that the charges are easily transferred to the bottom of the bed because of low particle resistance. When an open box is made of metal instead of acryl resin and grounded, the manganese ferrite particles will not hold their charges. In contrast, PTFE particles in a powder bed of certain thickness will remain charged even when using the metal box. The method for charging powder beds by APPJ should thus be changed according to particle resistance.

\section{Indirect charging of particles [28]}

When the direct charging of particles is applied to a continuous system, the APPJ needs to always be operated. In contrast, indirect charging will enable improving the flexibility of operation. For example, when the charges generated by the APPJ are deposited on a dielectric plate and then transferred to particles by moving the particles on the dielectric plate, indirect charging is realized.

\subsection{Experimental setup and procedure}

Fig. 17 shows a method for pre-charging the surface of the dielectric plate (PMMA or PVC). The dielectric plate of length $100 \mathrm{~mm}$, width $60 \mathrm{~mm}$, and thickness $1 \mathrm{~mm}$ is placed on a grounded metal plate. Two APPJ nozzles are horizontally placed at a height of $10 \mathrm{~mm}$ from the surface of the dielectric plate. The operating conditions are as follows: AC voltage is set at $5 \mathrm{kV}$ in peak and $6 \mathrm{kHz}$ and flow rate of helium gas is $1 \mathrm{SLM}$. A surface potential meter is used to quantify the charging.

Fig. 18 shows a schematic of the experimental setup for transferring charges to particles from the pre-charged dielectric plate. The plate is placed at an angle of $30^{\circ}$ from the horizontal plane. Non-charged manganese ferrite particles are continuously fed to the plate at $0.5-1.0$ $\mathrm{mg} / \mathrm{s}$, and the specific charge of the particles dropped from the plate is measured with a Faraday cup. 


\subsection{Experimental results and discussion}

First, a preliminary experiment to investigate the performance of the pre-charging is conducted. The surface potential of the dielectric plate increases with time and reaches the maximum value in $10 \mathrm{~s}$. After stopping the irradiation of the APPJ, the surface potential decreases to $80 \%$ in $10 \mathrm{~min}$ and $70 \%$ in $30 \mathrm{~min}$. These results indicate that the surface is quickly charged and gradually discharged; therefore, this method is applicable to pre-charging.

Fig. 19 shows the relationship between the surface potential of the dielectric plate and the DC bias voltage applied to the electrode in the APPJ nozzle. The irradiation time is set to $15 \mathrm{~s}$, and the measurement positions are located 30,50 , and $70 \mathrm{~mm}$ away in the longitudinal direction of the plate. The surface potential varies from -1.6 to $2.4 \mathrm{kV}$ according to the $\mathrm{DC}$ bias voltage and does not depend on the measurement positions. This result indicates that pre-charging can be controlled by the irradiation of the APPJ.

Fig. 20 shows the charge transferred from the pre-charged dielectric plate to the particles. The surface charge density of the particles is proportional to the surface potential of the dielectric plate irrespective of the material of the plate. Since the surface potential of the dielectric plate is controlled by the DC bias voltage, the particle charge can also be controlled by the same bias voltage. These experimental results imply that intermittent plasma operation can control continuous particle charge by combining the APPJ system and the inclined dielectric plate.

\section{Conclusions}

This article focuses on a review of the control of particle charging by an APPJ by three different methods. The specifications of the three systems, their mechanisms of charge transfer to particles, and methods for particle charge control are summarized as follows:

1) A nozzle having a cylindrical electrode structure in a dielectric tube of 8 -mm inner diameter was used to generate the APPJ. The typical operating conditions were as follows: AC 
voltage of $5 \mathrm{kV}$ in peak (at $6 \mathrm{kHz}$ ) and 1-SLM helium gas flow rate. By changing the DC bias voltage applied to the electrode, ions and/or electrons in the APPJ were arbitrarily extracted to the space close to the nozzle.

2) The extracted charges were directly deposited onto the particles. The process wherein the particles pass through the APPJ is not essential for particle charging. The charge transfer is aided by the electric field, i.e., the particle charging depends on the electric field based on the space charge and/or an externally applied electric field. Therefore, the particle charging is controlled by the DC bias voltage and/or externally applied voltage, irrespective of the physical properties of the particles themselves. The time period required for direct particle charging was a few seconds.

3) The charging of powder beds was also controlled directly by the APPJ. The effective charging surface area was approximately $0.01 \mathrm{~m}^{2}$ when supplying 1-SLM helium gas. To control the charging over a large area, a scanning device is required. For a powder with high resistivity, the upper layer particles were sufficiently charged in a few seconds. However, the lower layer particles were gradually charged over one minute. This is because the charges move through the particle surfaces having a certain electrical resistance in the powder bed. When the thickness of the powder bed exceeds $2 \mathrm{~mm}$, the charge transfer becomes difficult. For a powder with a low resistivity, the charges easily move to the lower layer particles.

4) When the direct charging of particles is applied to a continuous system, the APPJ needs to always be operated. In contrast, an indirect charge transfer enables improving the flexibility of operation. Since charges generated by the APPJ are deposited onto a dielectric plate and then transferred to particles by moving the particles on the dielectric plate, indirect charging is realized, and development of new methods is possible.

\section{Acknowledgment}


This work was supported by a JSPS KAKENHI Grant (Number JP17H03442).

\section{References}

[1] A. Schutze, J.Y. Jeong, S.E. Babayan, J. Park, G.S. Selwyn, R.F. Hicks, The atmospheric-pressure plasma jet: a review and comparison to other plasma sources, IEEE Trans. Plasma Sci. 26 (1998) 1685-1694.

[2] F. Massines, C. Sarra-Bournet, F. Fanelli, N. Naudé, N. Gherardi, Atmospheric pressure low temperature direct plasma technology: status and challenges for thin film deposition, Plasma Process. Polym. 9 (2012) 1041-1073.

[3] C. Cheng, Z. Liye, R.-J. Zhan, Surface modification of polymer fibre by the new atmospheric pressure cold plasma jet, Surf. Coat. Tech., 200 (2006) 6659-6665.

[4] J. Ehlbeck, U. Schnabel, M. Polak, J. Winter, Th. von Woedtke, R. Brandenburg, T. von dem Hagen, K.-D. Weltmann, Low temperature atmospheric pressure plasma sources for microbial decontamination, J. Phys. D: Appl. Phys., 44 (2011) 013002.

[5] M. Keidar, A. Shashurin, O. Volotskova, M.A. Stepp, P. Srinivasan, A. Sandler, B. Trink, Cold atmospheric plasma in cancer therapy, Phys. Plasmas, 20 (2013) 057101.

[6] M. Teschke, J. Kedzierski, E.G. Finantu-Dinu, D. Korzec, J. Engemann, High-speed photographs of a dielectric barrier atmospheric pressure plasma jet, IEEE Trans. Plasma Sci. 33 (2005) 310-311.

[7] X. Lu, M. Laroussi, Dynamics of an atmospheric pressure plasma plume generated by submicrosecond voltage pulses, J. Appl. Phys. 100 (2006) 063302.

[8] J.L. Walsh, , F. Iza, N.B. Janson, V.J. Law, M.G. Kong, Three distinct modes in a cold atmospheric pressure plasma jet, J. Phys. D: Appl. Phys. 43 (2010) 075201.

[9] G.V. Naidis, Modelling of plasma bullet propagation along a helium jet in ambient air, J. Phys. D: Appl. Phys. 44 (2011) 215203.

[10] X. Lu, M. Laroussi, V. Puech, On atmospheric-pressure non-equilibrium plasma jets 
and plasma bullets, Plasma Sources Sci. T. 21 (2012) 034005.

[11] J-P. Boeuf, L.L. Yang, L.C. Pitchford, Dynamics of a guided streamer ('plasma bullet') in a helium jet in air at atmospheric pressure, J. Phys. D: Appl. Phys. 46 (2013) 015201.

[12] J. Winter, R. Brandenburg, K.D. Weltmann, Atmospheric pressure plasma jets: an overview of devices and new directions, Plasma Sources Sci. T. 24 (2015) 064001.

[13] T. Matsuyama, M. Ohtsuka, H. Yamamoto, Measurement of force curve due to electrostatic charge on a single particle using atomic force microscope, J. Soc. Powder Technol., Japan 43 (2006) 174-180.

[14] M. Takeuchi, Adhesion forces of charged particles, Chem. Eng. Sci. 61 (2006) 22792289.

[15] S. Matsusaka, H. Maruyama, T. Matsuyama, M. Ghadiri, Triboelectric charging of powders: a review, Chem. Eng. Sci. 65 (2010) 5781-5807.

[16] I. Adhiwidjaja, S. Matsusaka, S. Yabe, H. Masuda, Simultaneous phenomenon of particle deposition and reentrainment in charged aerosol flow: effects of particle charge and external electric field on the deposition layer, Adv. Powder Technol. 11 (2000) 221233.

[17] H. Masuda, S. Matsusaka, S. Nagatani, Measurements of powder flow rate in gas-solids pipe flow based on the static electrification of particles, Adv. Powder Technol. 5 (1994) $241-254$.

[18] H. Masuda, S. Matsusaka, H. Shimomura, Measurement of the mass flow rate of a polymer powder based on the static electrification of particles, Adv. Powder Technol. 9 (1998) 169-179.

[19] S. Matsusaka, H. Fukuda, Y. Sakura, H. Masuda, M. Ghadiri, Analysis of pulsating electric signals generated in gas-solids pipe flow, Chem. Eng. Sci. 63 (2008) 1353-1360.

[20] L.B. Schein, Recent advances in our understanding of toner charging, J. Electrostat. 46 (1999) 29-36.

[21] S. Matsusaka, D. Wei, M. Yasuda, S. Sasabe, Adhesive strength distribution of charged 
particles on metal substrate in external electric field, Adv. Powder Technol. 26 (2015) $149-155$.

[22] P. Bunchatheeravate, J. Curtis, Y. Fujii, S. Matsusaka, Prediction of particle charging in a dilute pneumatic conveying system, AIChE J. 59 (2013) 2308-2316.

[23] M. Mizutani, M. Yasuda, S. Matsusaka, Advanced characterization of particles triboelectrically charged by a two-stage system with vibrations and external electric fields, Adv. Powder Technol. 26 (2015) 454-461.

[24] S. Matsusaka, M. Oki, H. Masuda, Control of electrostatic charge on particles by impact charging, Adv. Powder Technol. 18 (2007) 229-244.

[25] S. Matsusaka, Control of particle tribocharging, KONA Powder Part. J. 29 (2011) 2738.

[26] S. Matsusaka, A. Noguchi, S. Kitajima, M. Yasuda, Control of electrostatic charge on particles by atmospheric pressure plasma jet, Kagaku Kogaku Ronbun. 42 (2016) 100106.

[27] S. Matsusaka, A. Noguchi, S. Kitajima, M. Yasuda, Electric charging of powder bed by ion and/or electron irradiation using atmospheric pressure plasma jet, Kagaku Kogaku Ronbun. 42 (2016) 137-141.

[28] S. Kitajima, M. Yasuda, S. Matsusaka, Controlling electrostatic charge on particles moving on a dielectric plate by charge extraction using an atmospheric pressure plasma jet, Kagaku Kogaku Ronbun. 43 (2017) 16-21.

[29] T. Murakami, K. Niemi, T. Gans, D. O'Connell, W.G. Graham, Chemical kinetics and reactive species in atmospheric pressure helium-oxygen plasmas with humid-air impurity, Plasma Sources Sci. T. 22 (2013) 015003. 
Table 1 Physical properties of powders used

\begin{tabular}{lccccccc}
\hline Materials & Shape & $D_{\mathrm{p} 50}(\mu \mathrm{m})$ & $\sigma_{\mathrm{g}}(-)$ & $D_{\mathrm{sv}}(\mu \mathrm{m})$ & $\rho_{\mathrm{p}}\left(\mathrm{kg} / \mathrm{m}^{3}\right)$ & $\rho_{\mathrm{v}}(\Omega \cdot \mathrm{m})$ & $\rho_{\mathrm{s}}(\Omega)$ \\
\hline Manganese ferrite & Spherical & 79 & 1.2 & 86 & 4900 & 7.6 & $3.3 \times 10^{3}$ \\
Manganese ferrite coated & Spherical & 81 & 1.2 & 88 & 4800 & $2.8 \times 10^{3}$ & $2.4 \times 10^{6}$ \\
with acrylic resin & Spherical & 51 & 1.2 & 55 & 3900 & $7.1 \times 10^{7}$ & $1.3 \times 10^{8}$ \\
Alumina & Irregular & 290 & 1.4 & 385 & 880 & $>10^{16}$ & $>10^{16}$ \\
PTFE (aggregate) &
\end{tabular}

$D_{\mathrm{p} 50}$ : number median particle diameter, $\sigma_{\mathrm{g}}$ : geometric standard deviation of particle diameter, $D_{\mathrm{sv}}$ : Sauter diameter $=D_{\mathrm{p} 50} \exp \left(2.5 \ln ^{2} \sigma_{\mathrm{g}}\right), \rho_{\mathrm{p}}$ : particle density, $\rho_{\mathrm{v}}$ : volume resistivity, $\rho_{\mathrm{s}}$ : surface resistivity. 


\section{List of figures}

Fig. 1. APPJ system for extracting charges.

Fig. 2. Effect of DC bias voltage on space charge.

Fig. 3. Photographs of APPJs with different flow rates of helium gas $\left(V_{\mathrm{b}}=+5 \mathrm{kV}, \varphi=65 \%\right)$.

Fig. 4. Two-dimensional distribution of detected currents $\left(V_{\mathrm{b}}=+5 \mathrm{kV}, \varphi=65 \pm 5 \%\right)$.

Fig. 5. Experimental setup for directly charging particles by APPJ.

Fig. 6. Effect of vertical distance between APPJ nozzle and plate on particle charging.

Fig. 7. Effect of DC bias voltage on particle surface charge density.

Fig. 8. Particle surface charge densities of different materials.

Fig. 9. Effect of external voltage on particle surface charge density.

Fig. 10. Effect of helium flow rate on particle surface charge density.

Fig. 11. Experimental setup for directly charging a powder bed by APPJ.

Fig. 12. Effective area for the electric charging of powder bed by APPJ.

Fig. 13. Effect of irradiation time of APPJ on particle charging (thickness of powder bed: 2 $\mathrm{mm})$.

Fig. 14. Effect of powder bed thickness on particle charging (PTFE).

Fig. 15. Effect of powder bed thickness on weight ratios of upper layer particles to total number of particles.

Fig. 16. Effect of powder bed thickness on particle charging (manganese ferrite).

Fig. 17. Method for pre-charging dielectric plate by APPJ.

Fig. 18. Experimental setup for transferring charges to particles from pre-charged dielectric plate.

Fig. 19. Relationship between surface potential of the dielectric plate and DC bias voltage applied to the electrode in the APPJ nozzle.

Fig. 20. Relationship between the surface charge densities of particles and surface potential of the dielectric plate. 
Mass flow controller

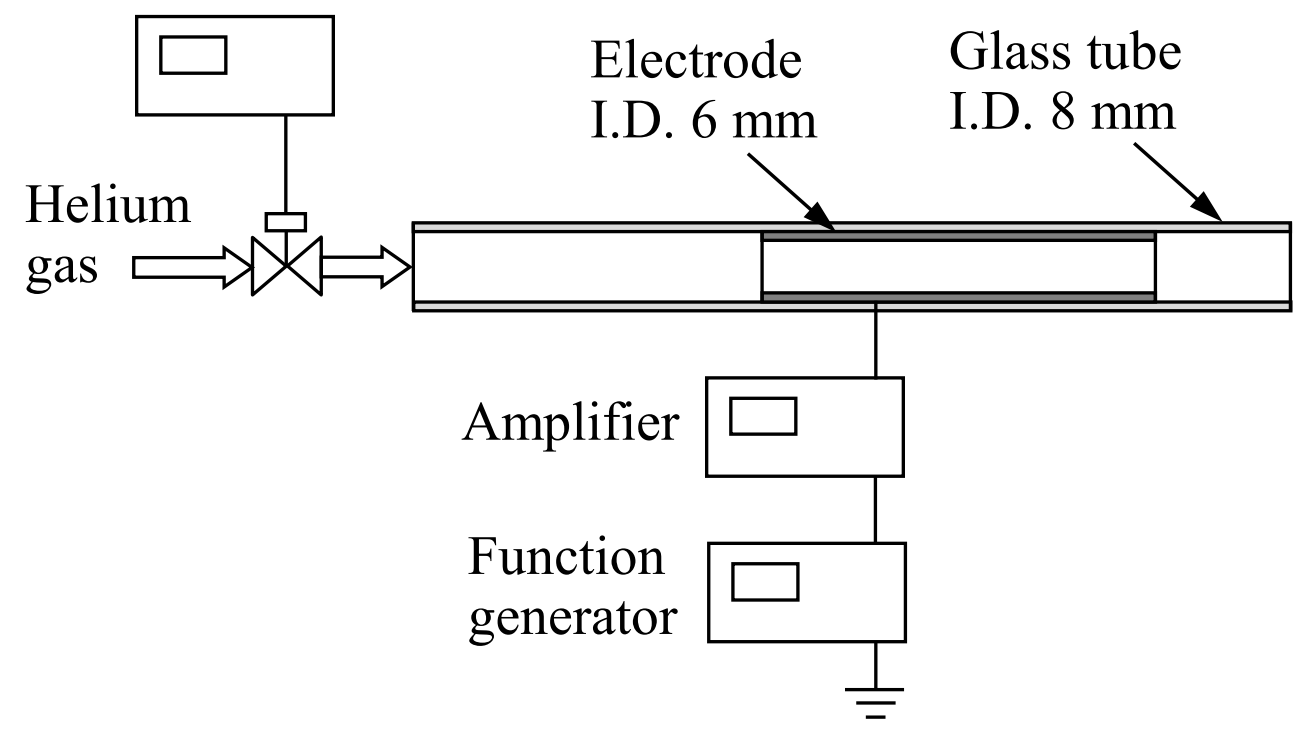




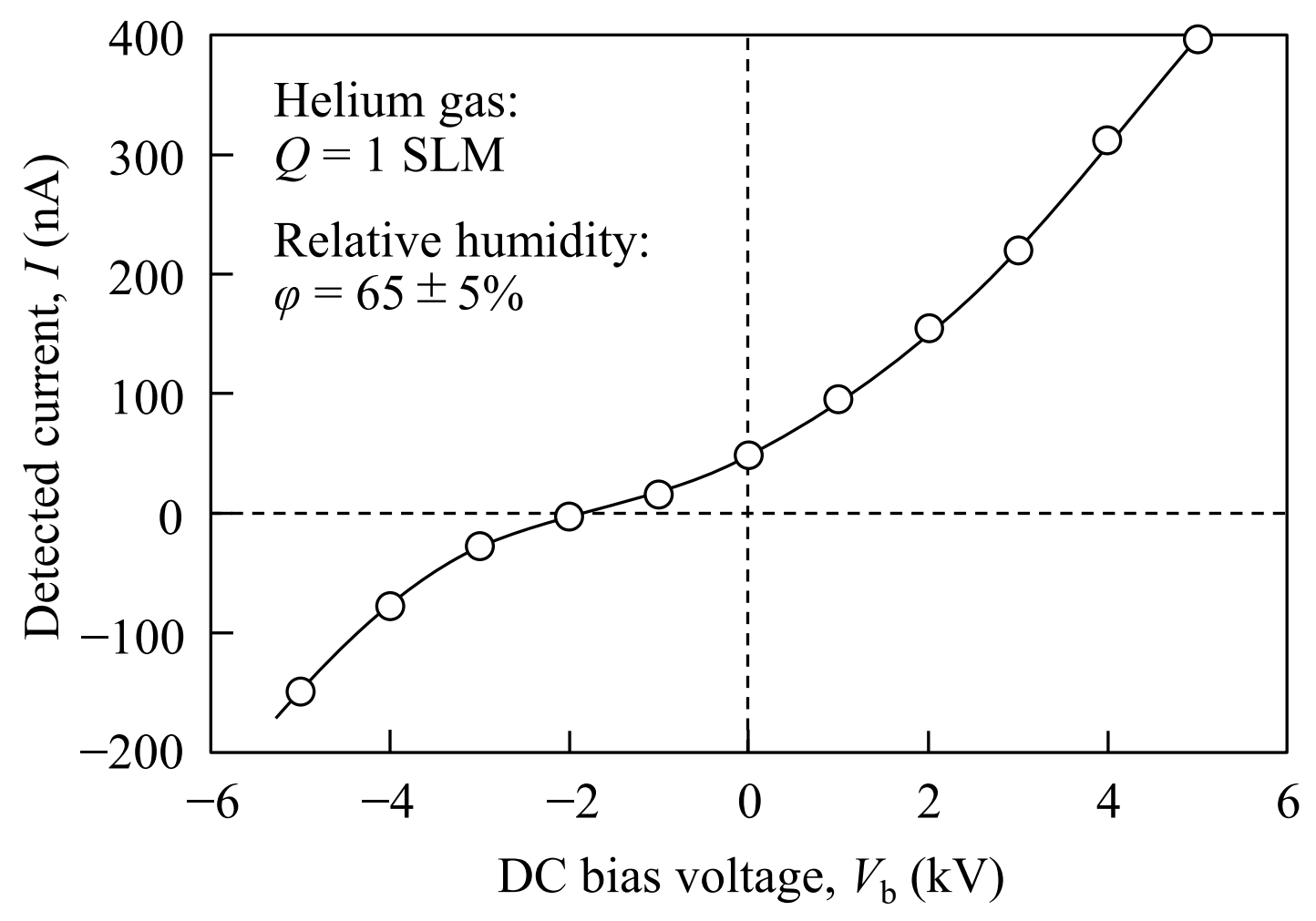

Fig. 2. Effect of DC bias voltage on space charge. 


\section{SLM}

5 SLM

10 SLM

Fig. 3. Photographs of APPJs with different flow rates of helium gas $\left(V_{\mathrm{b}}=+5 \mathrm{kV}, \varphi=65 \%\right)$. 
(a)
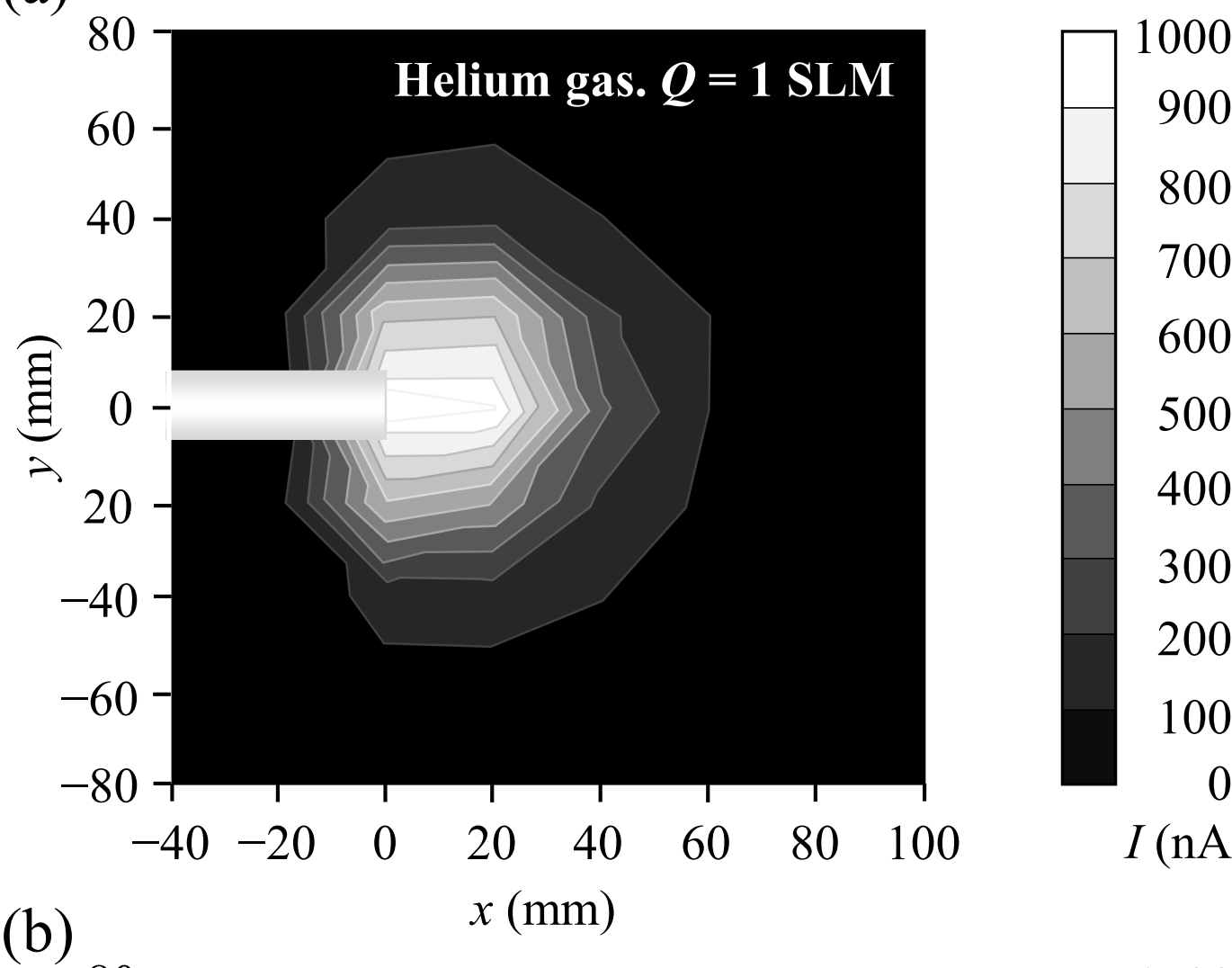

$I(\mathrm{nA})$

(b)
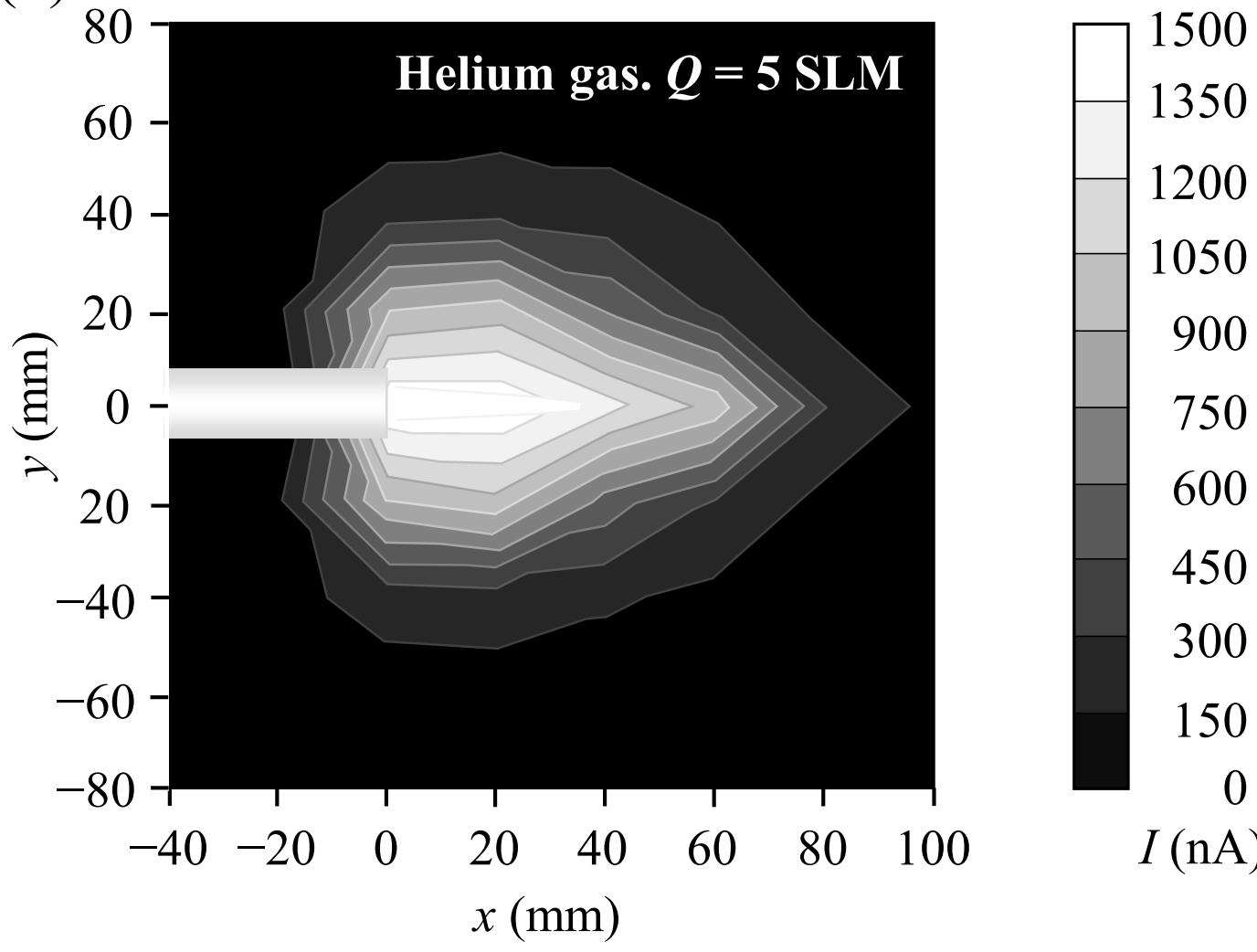

$I(\mathrm{nA})$

Fig. 4. Two-dimensional distribution of detected currents $\left(V_{\mathrm{b}}=+5 \mathrm{kV}, \varphi=65 \pm 5 \%\right)$. 


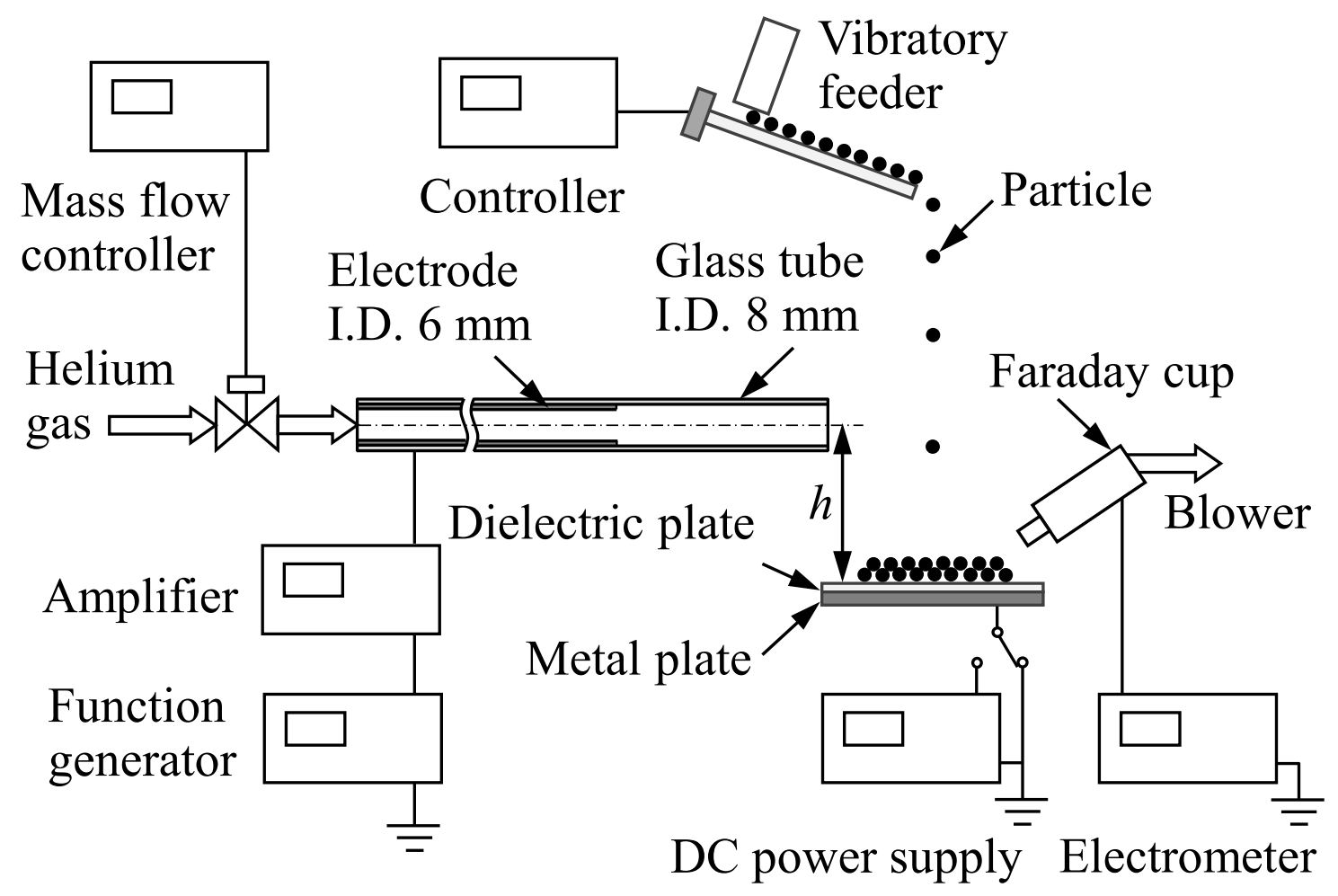

Fig. 5. Experimental setup for directly charging particles by APPJ. 


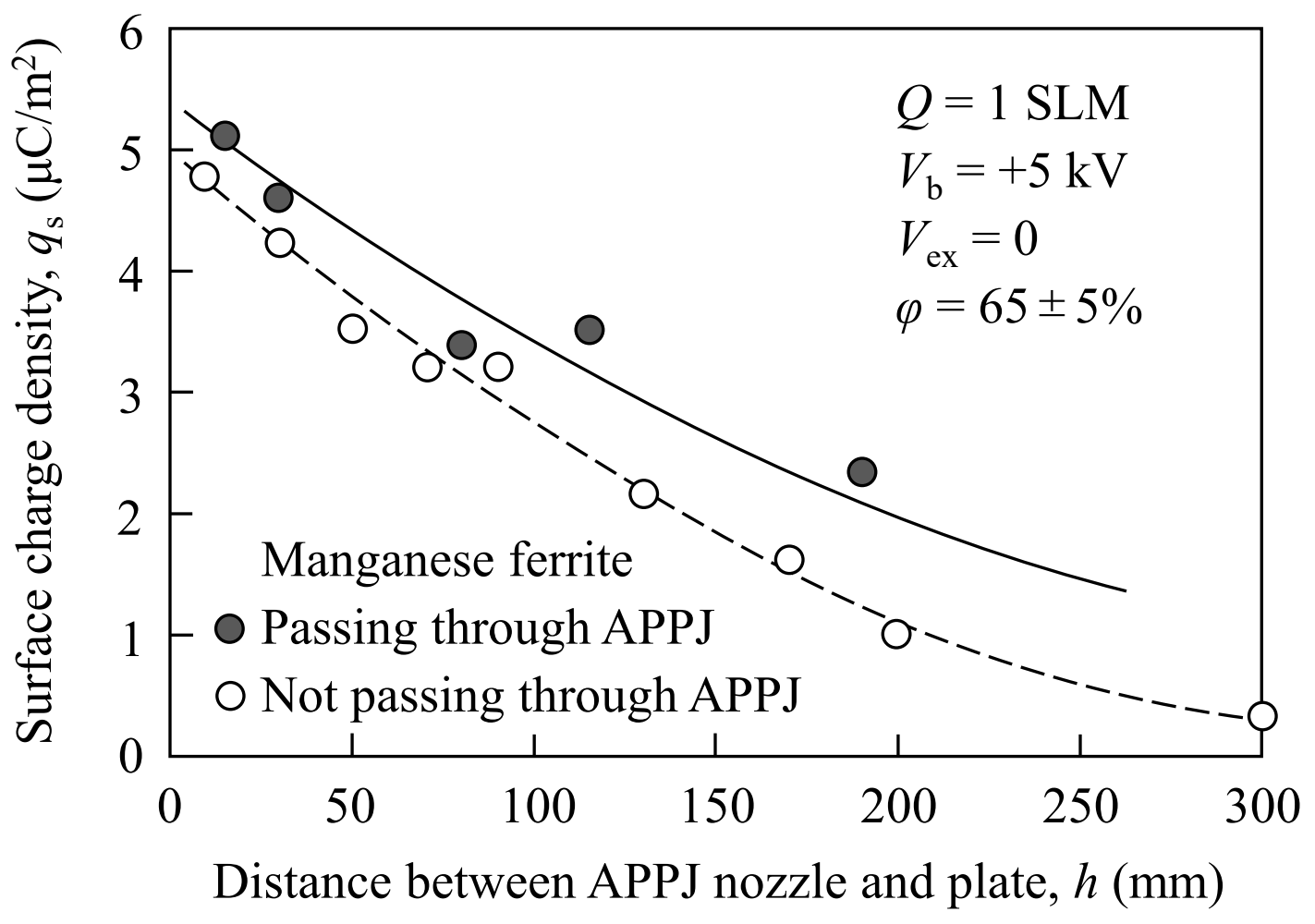

Fig. 6. Effect of vertical distance between APPJ nozzle and plate on particle charging. 


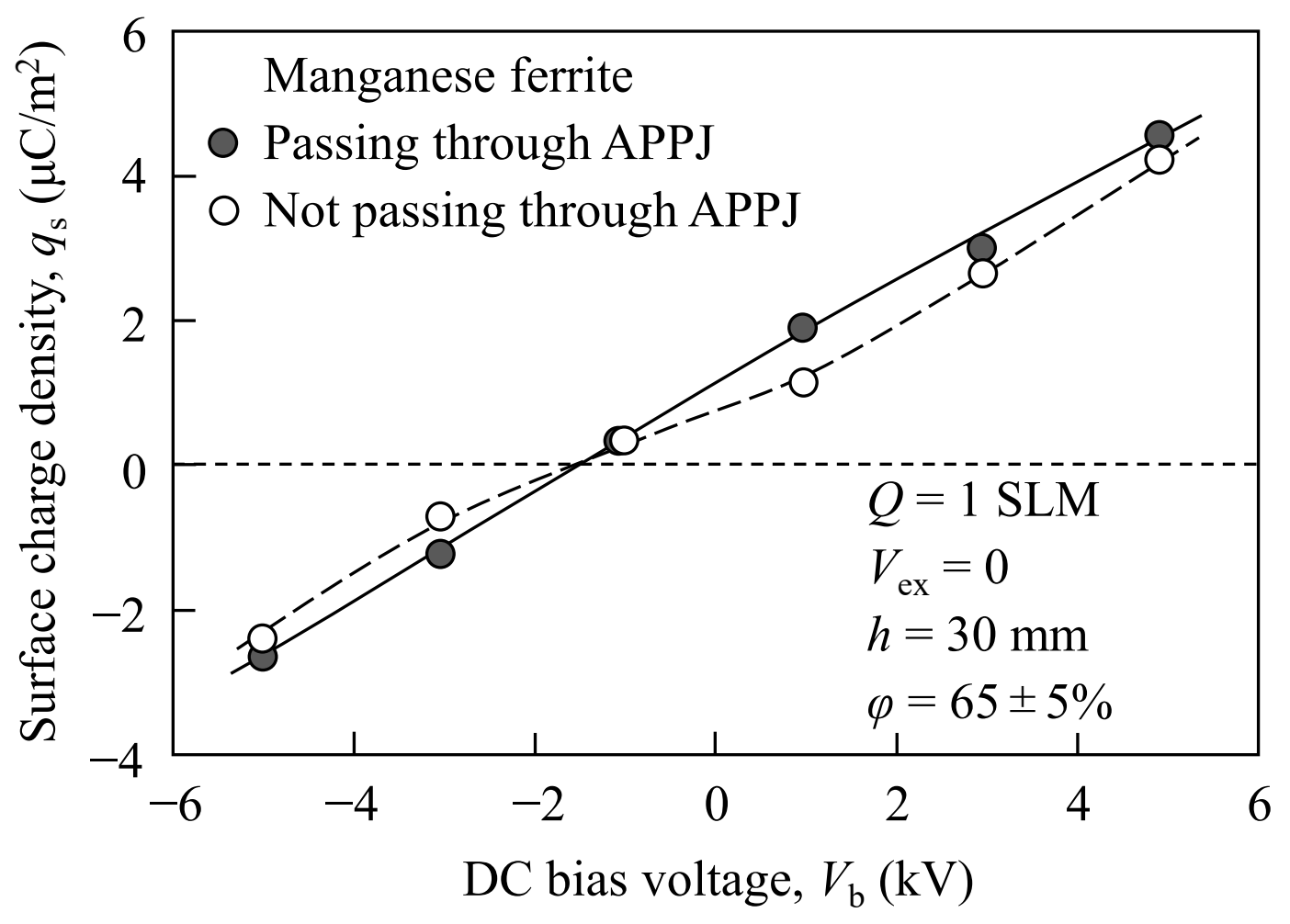

Fig. 7. Effect of DC bias voltage on particle surface charge density. 


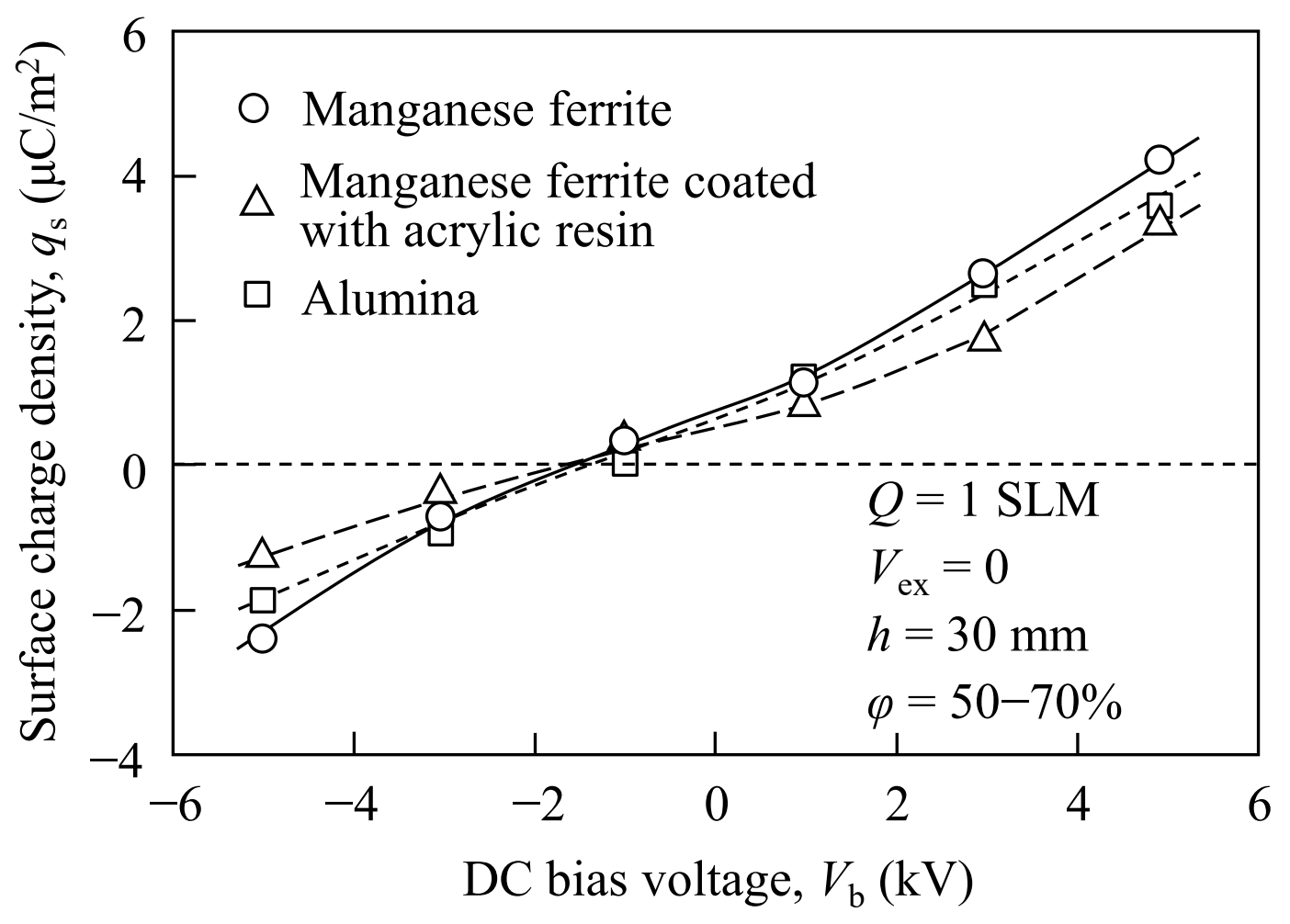

Fig. 8. Particle surface charge densities of different materials. 


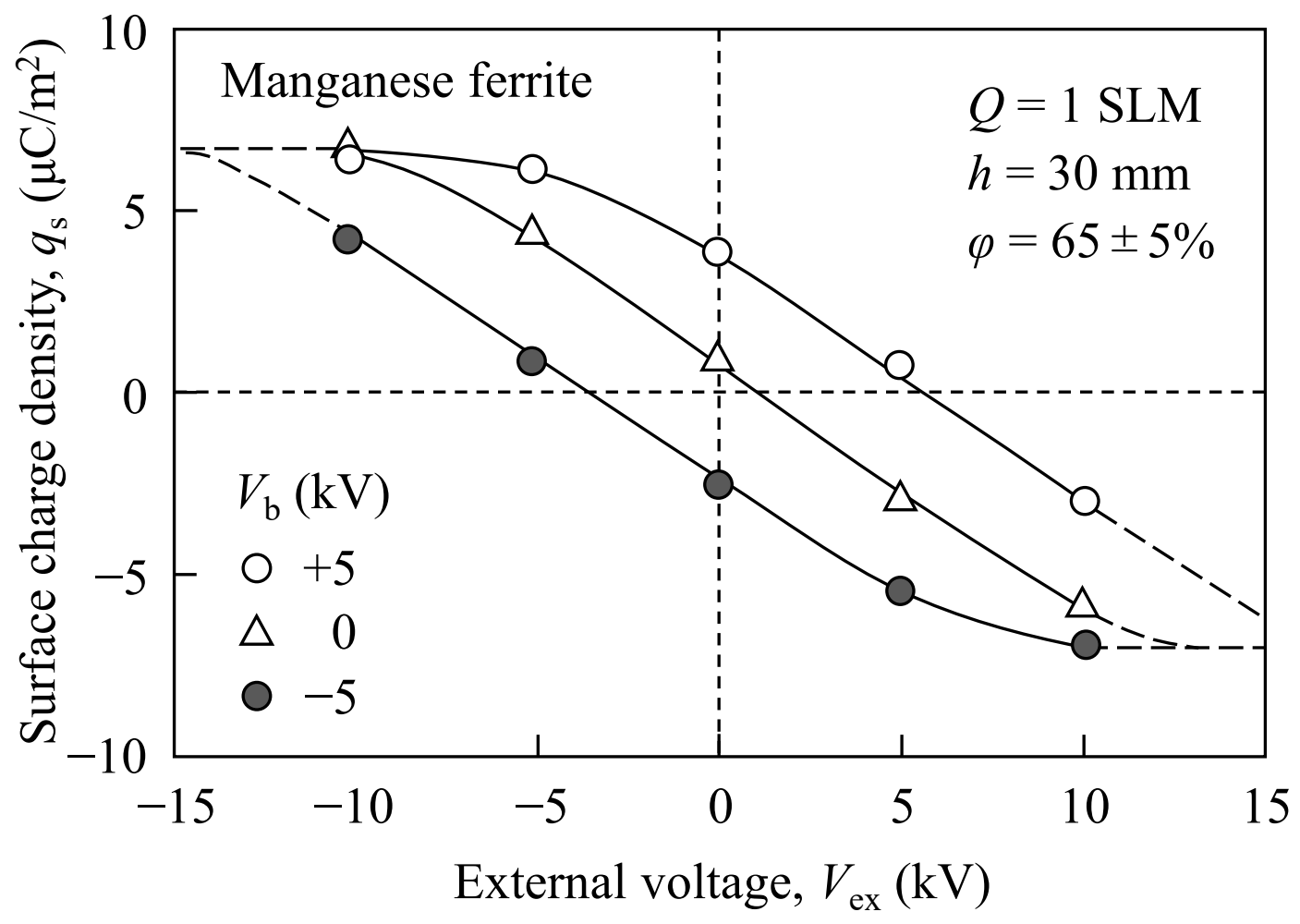

Fig. 9. Effect of external voltage on particle surface charge density. 


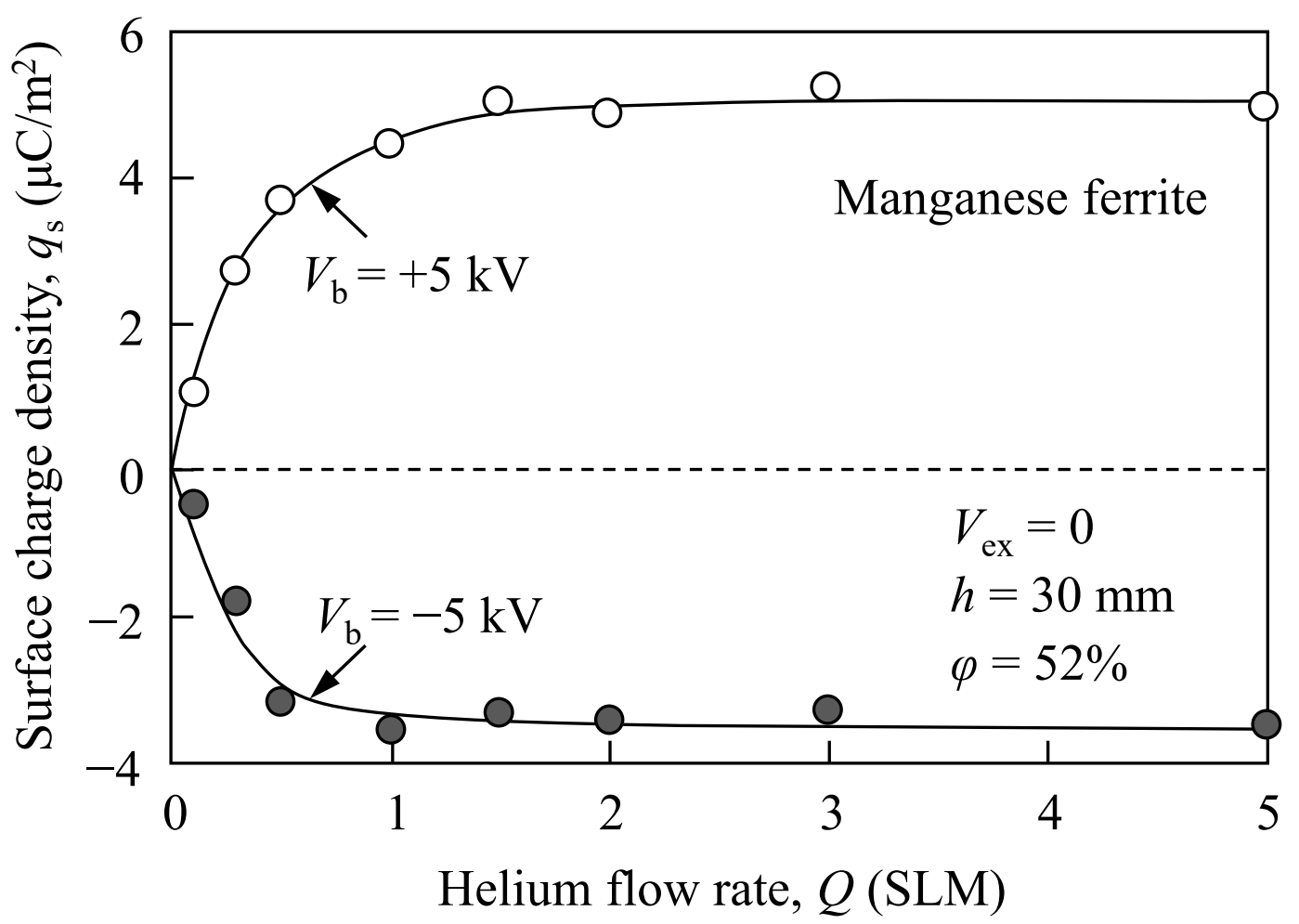

Fig. 10. Effect of helium flow rate on particle surface charge density. 

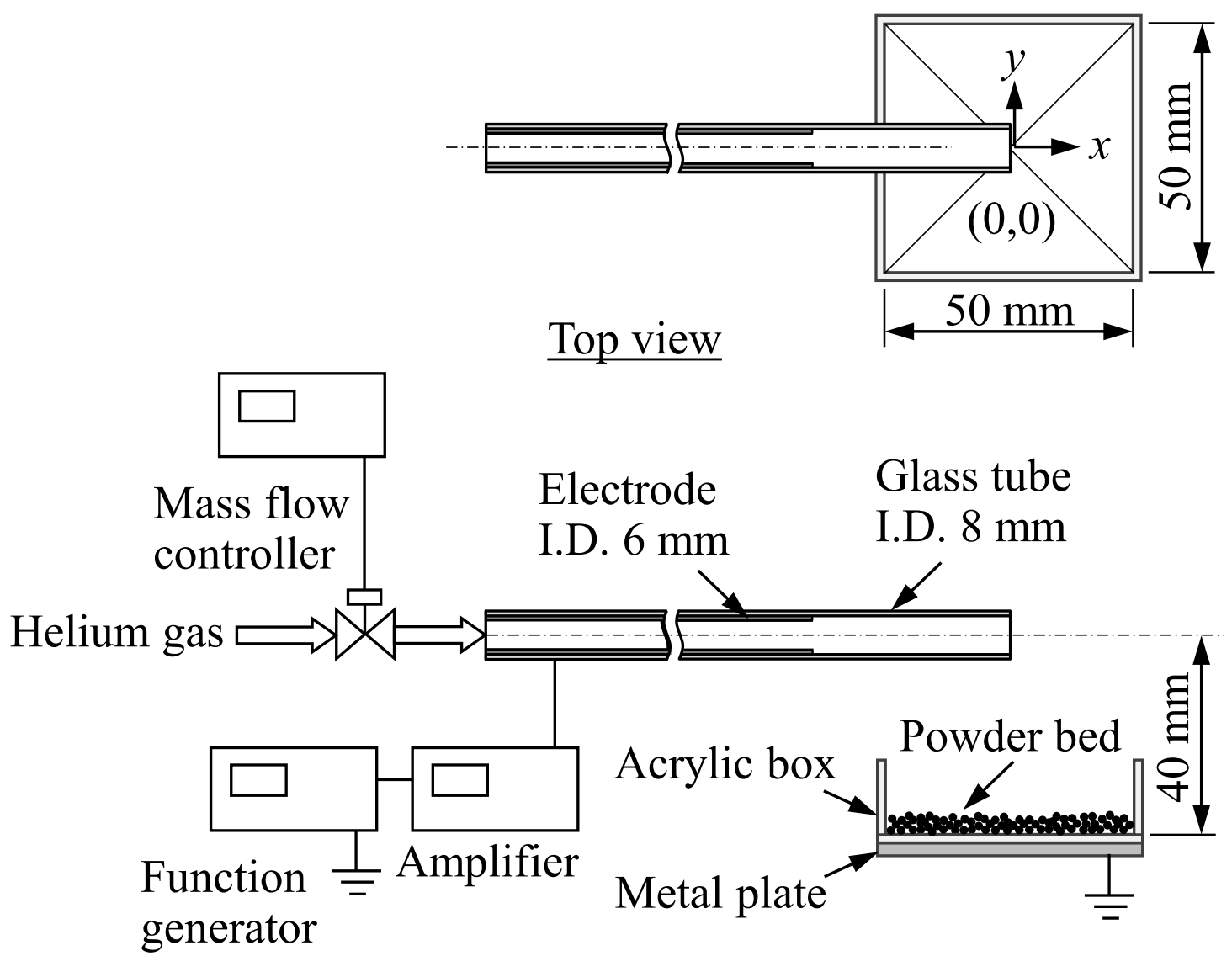

$\underline{\text { Side view }}$

Fig. 11. Experimental setup for directly charging a powder bed by APPJ. 


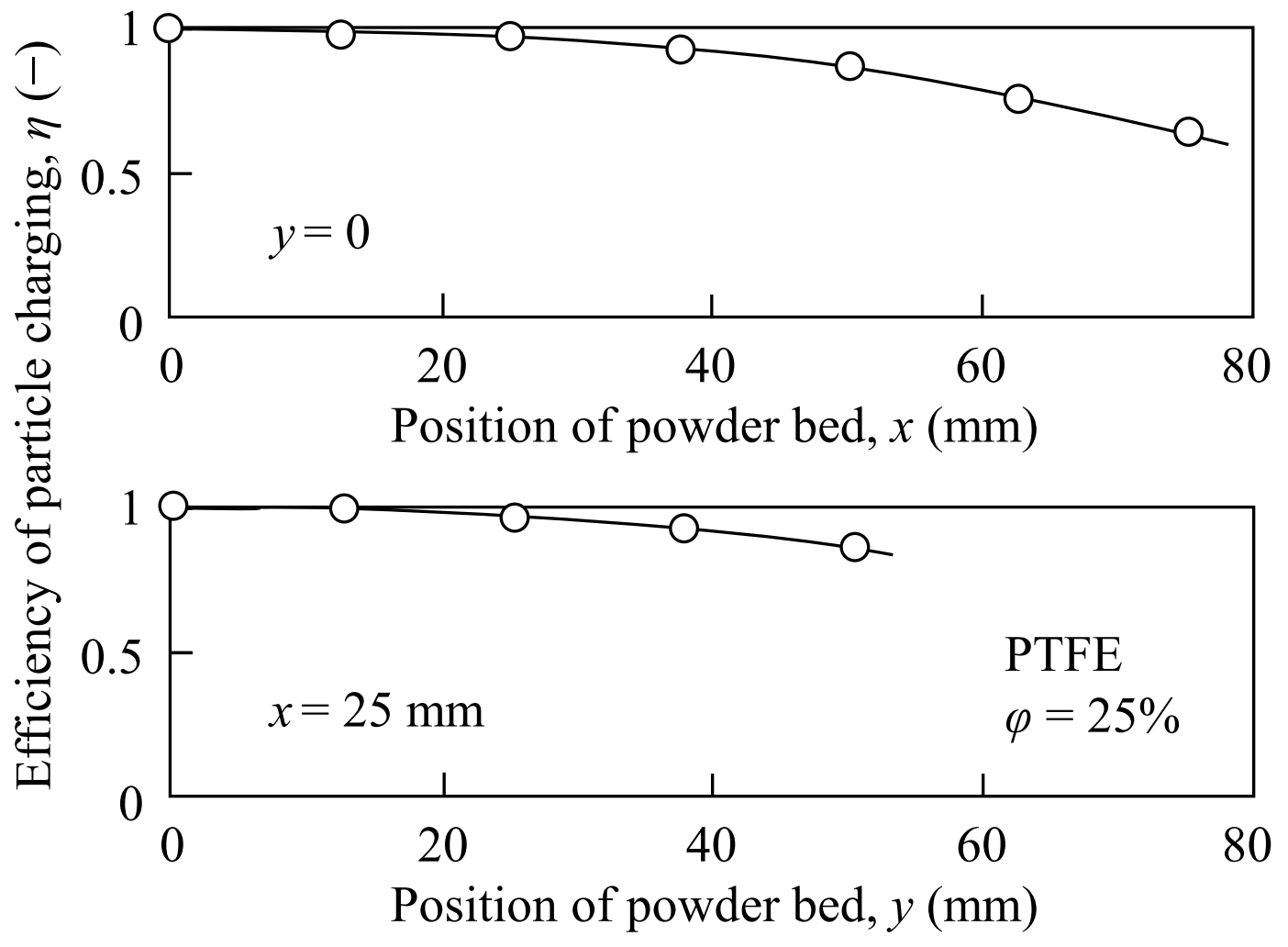

Fig. 12. Effective area for the electric charging of powder bed by APPJ. 


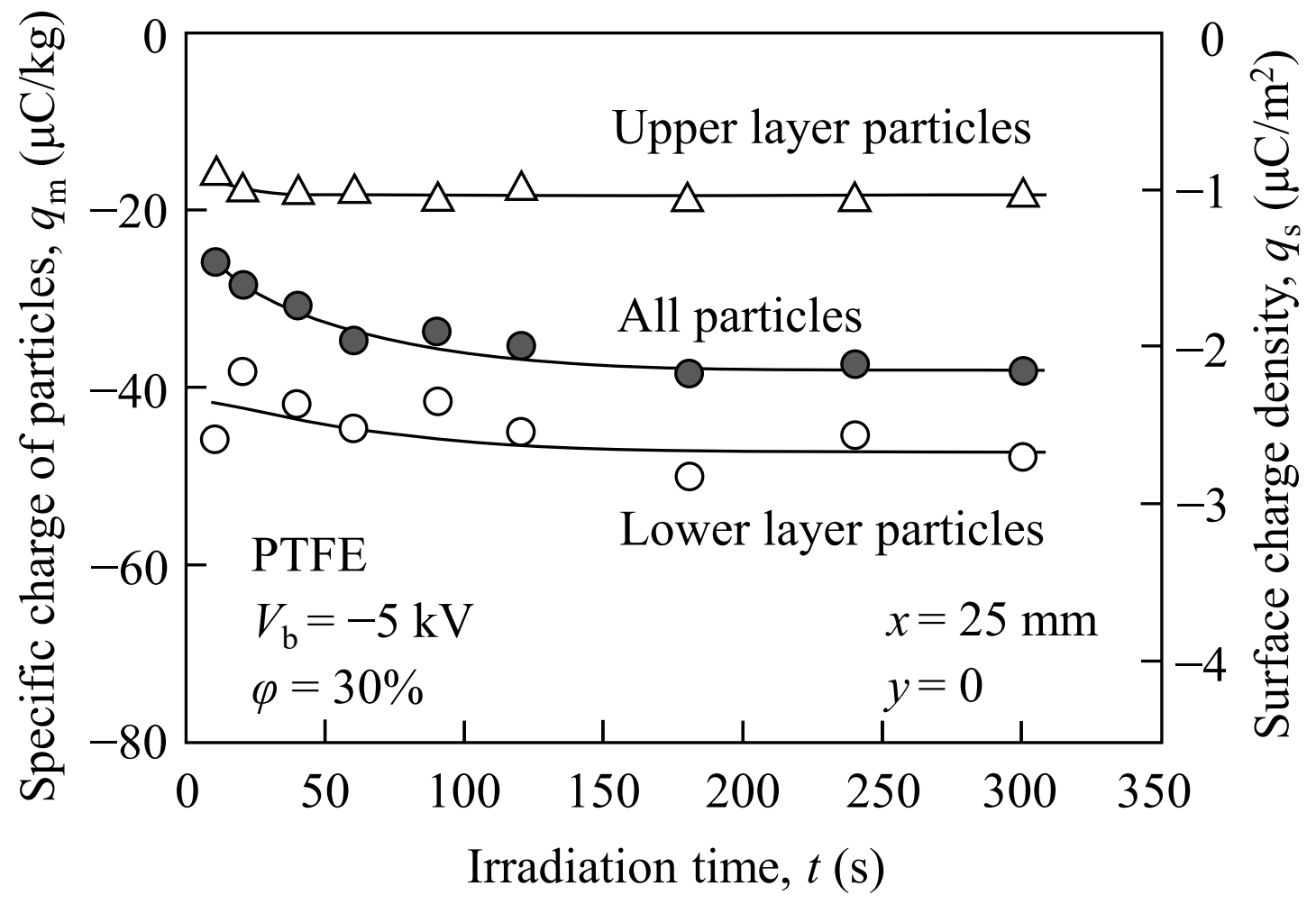

Fig. 13. Effect of irradiation time of APPJ on particle charging (the thickness of powder bed: $2 \mathrm{~mm}$ ). 


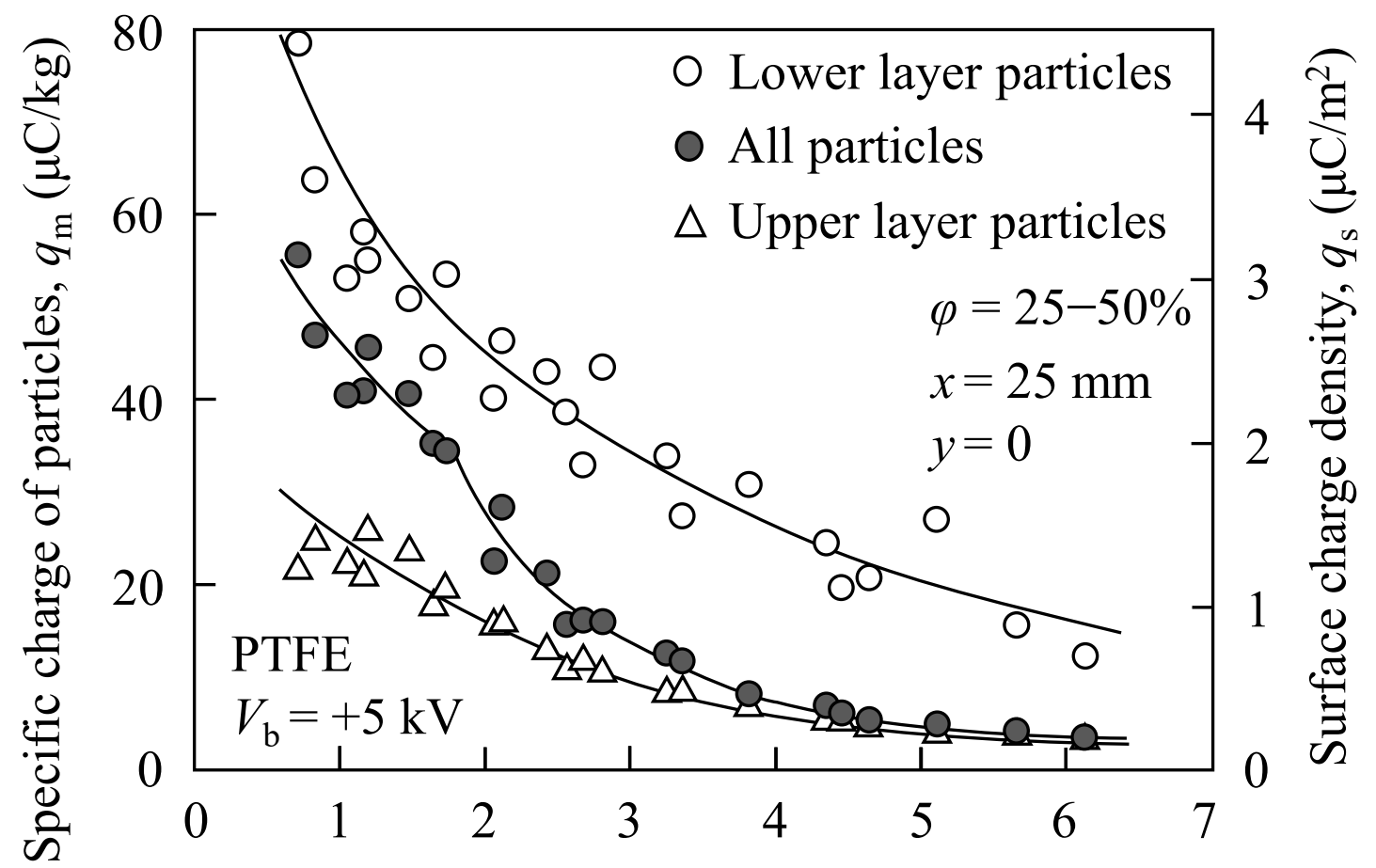

Thickness of powder bed, $t_{\mathrm{P}}(\mathrm{mm})$

Fig. 14. Effect of powder bed thickness on particle charging (PTFE). 


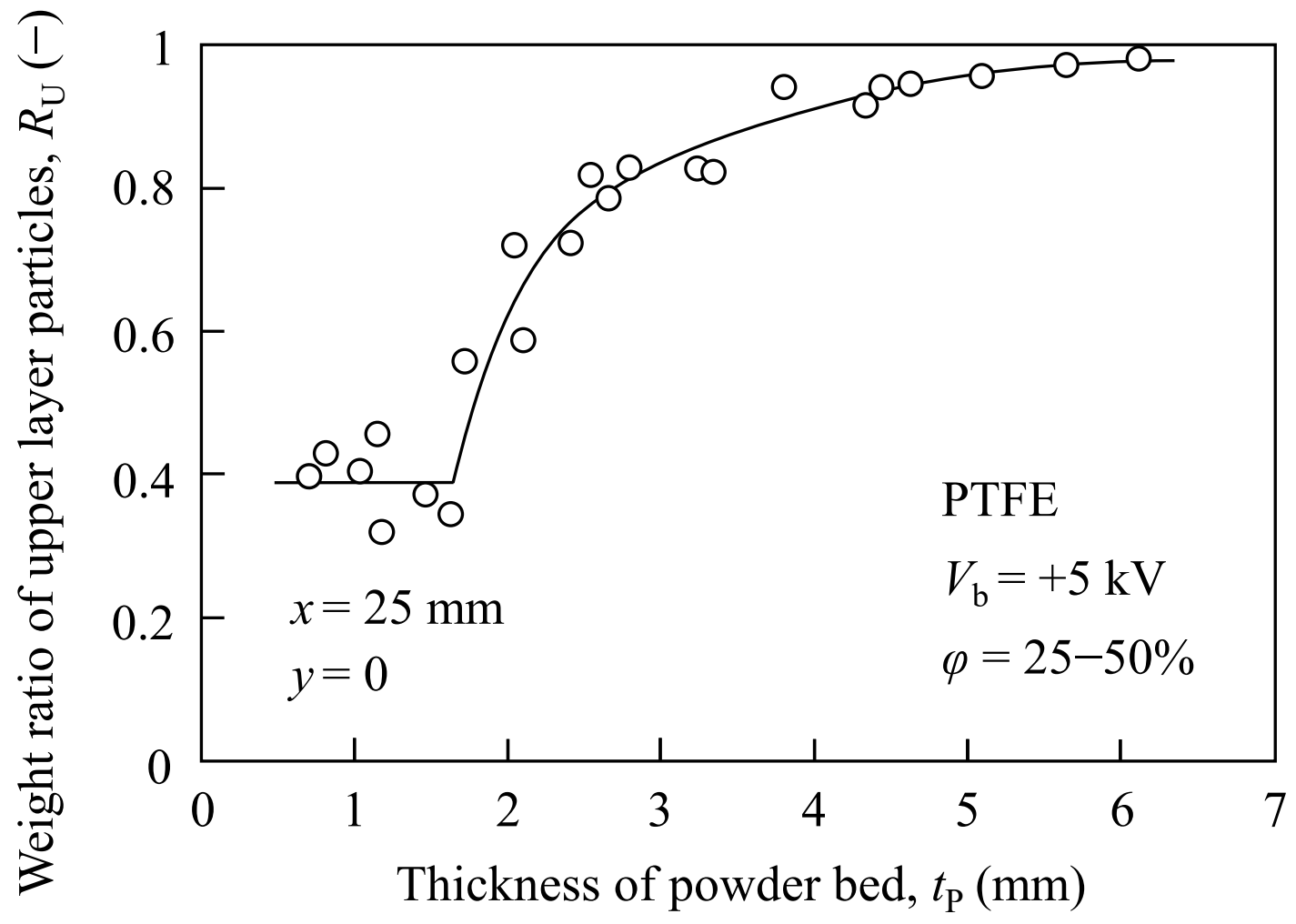

Fig. 15. Effect of powder bed thickness on weight ratios of upper layer particles to total number of particles. 


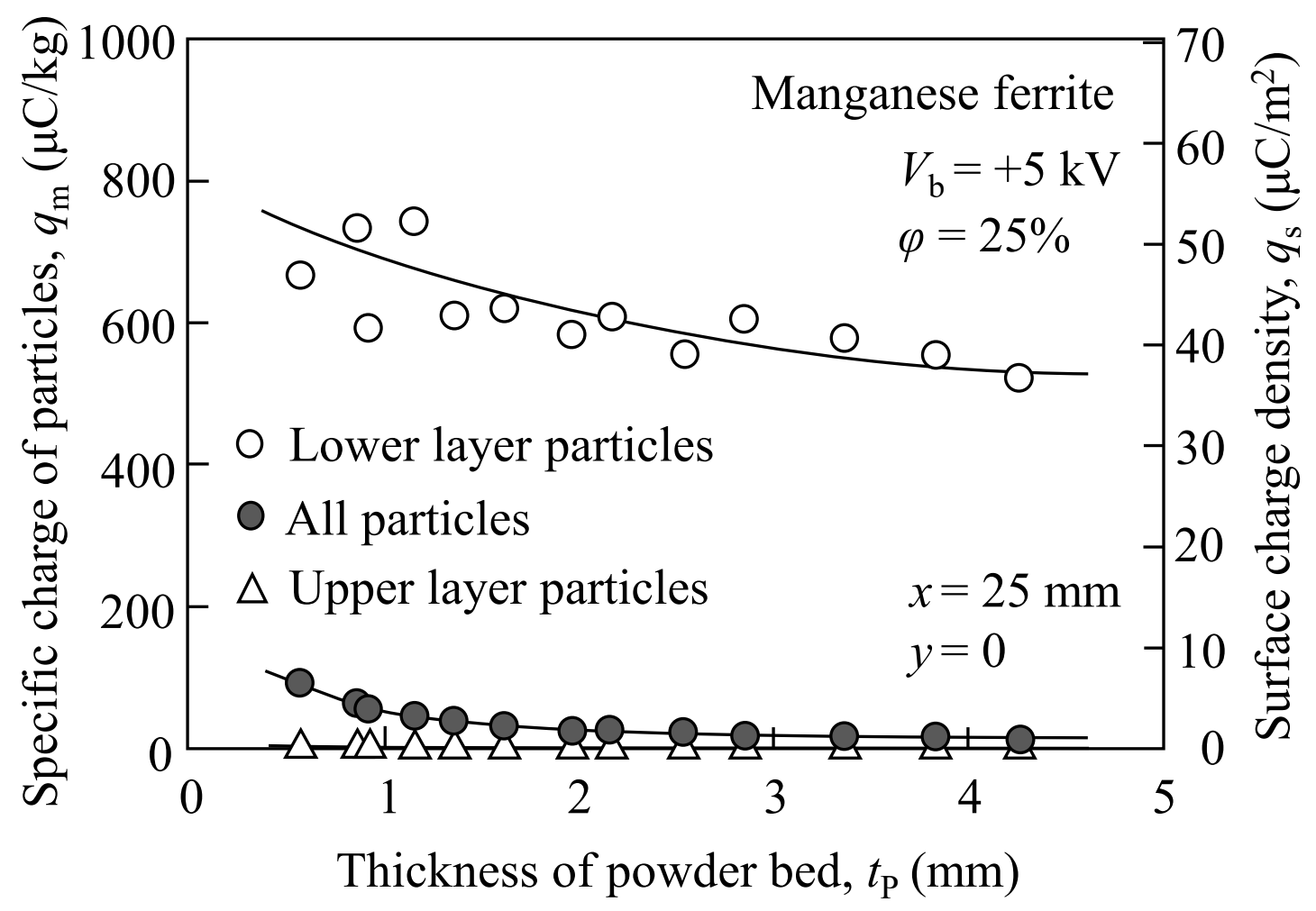

Fig. 16. Effect of powder bed thickness on particle charging (manganese ferrite). 


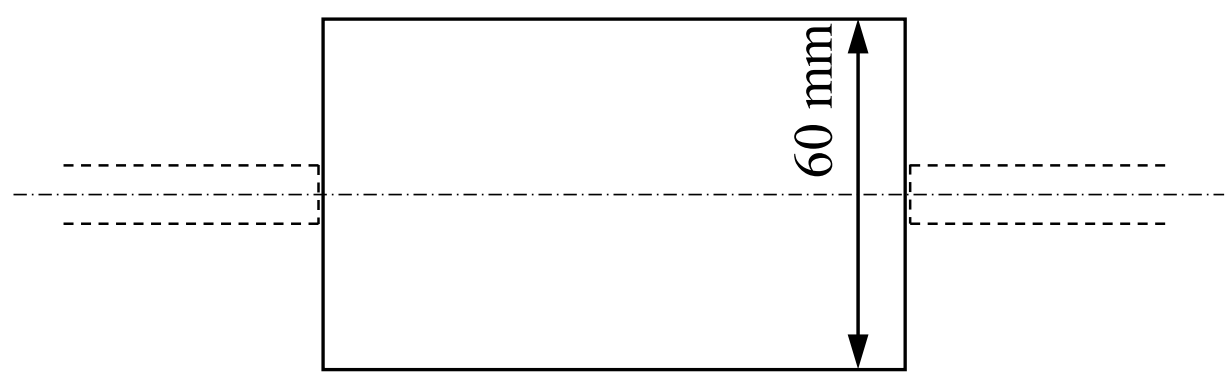

(1) Top view

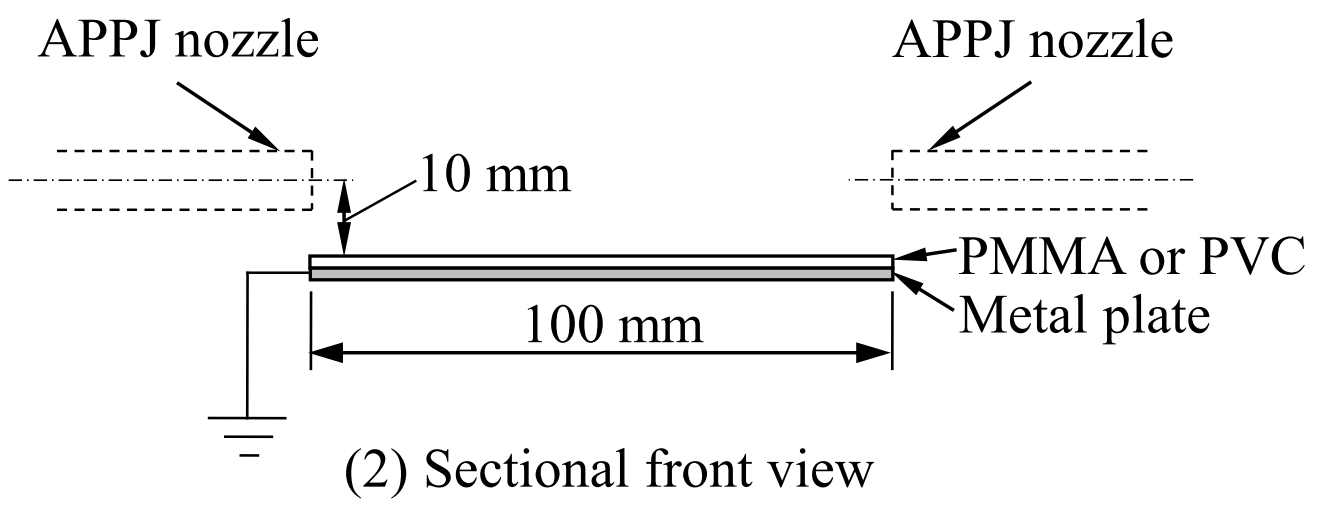

Fig. 17. Method for pre-charging dielectric plate by APPJ. 


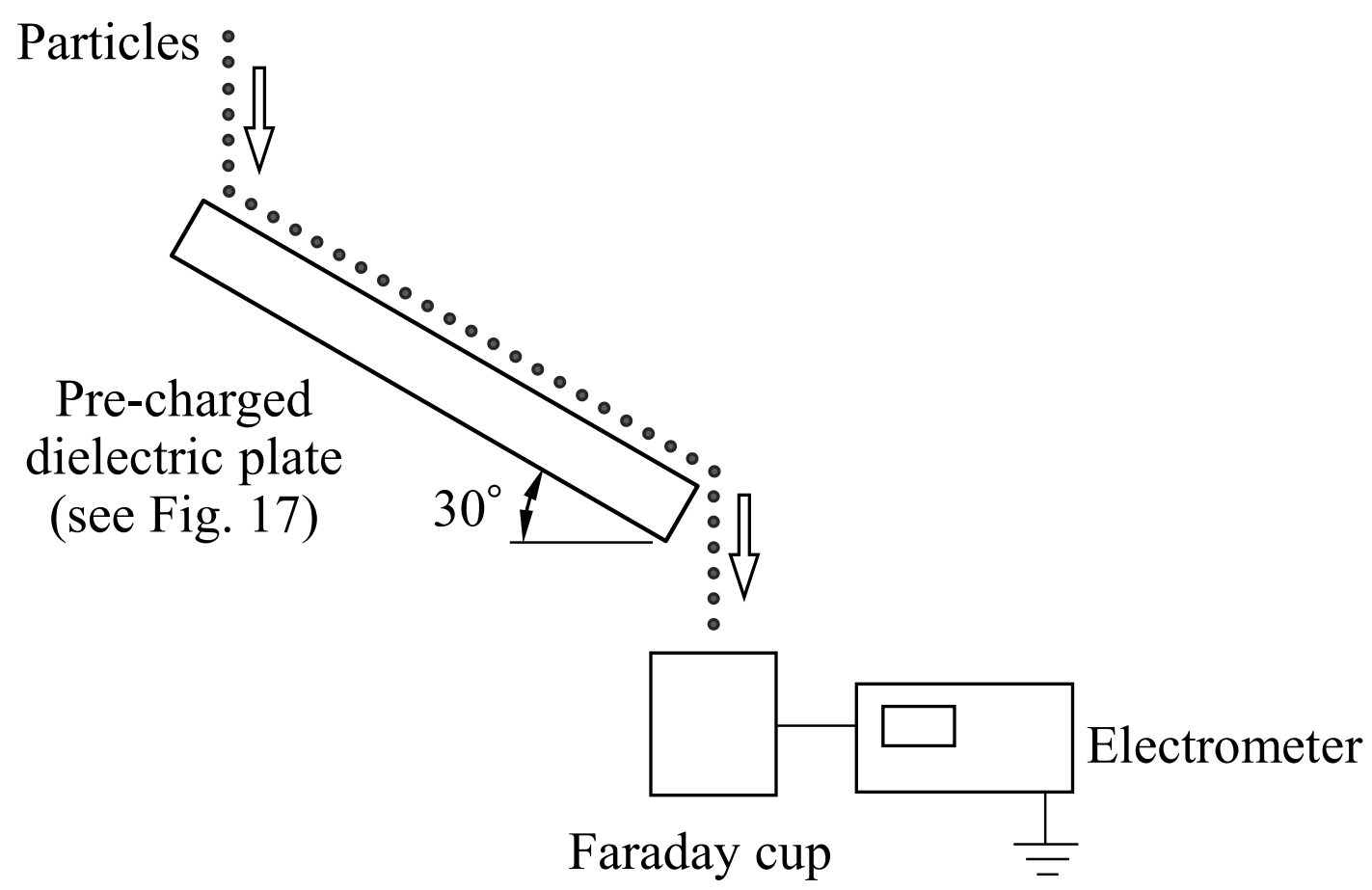

Fig. 18. Experimental setup for transferring charges to particles from pre-charged dielectric plate. 


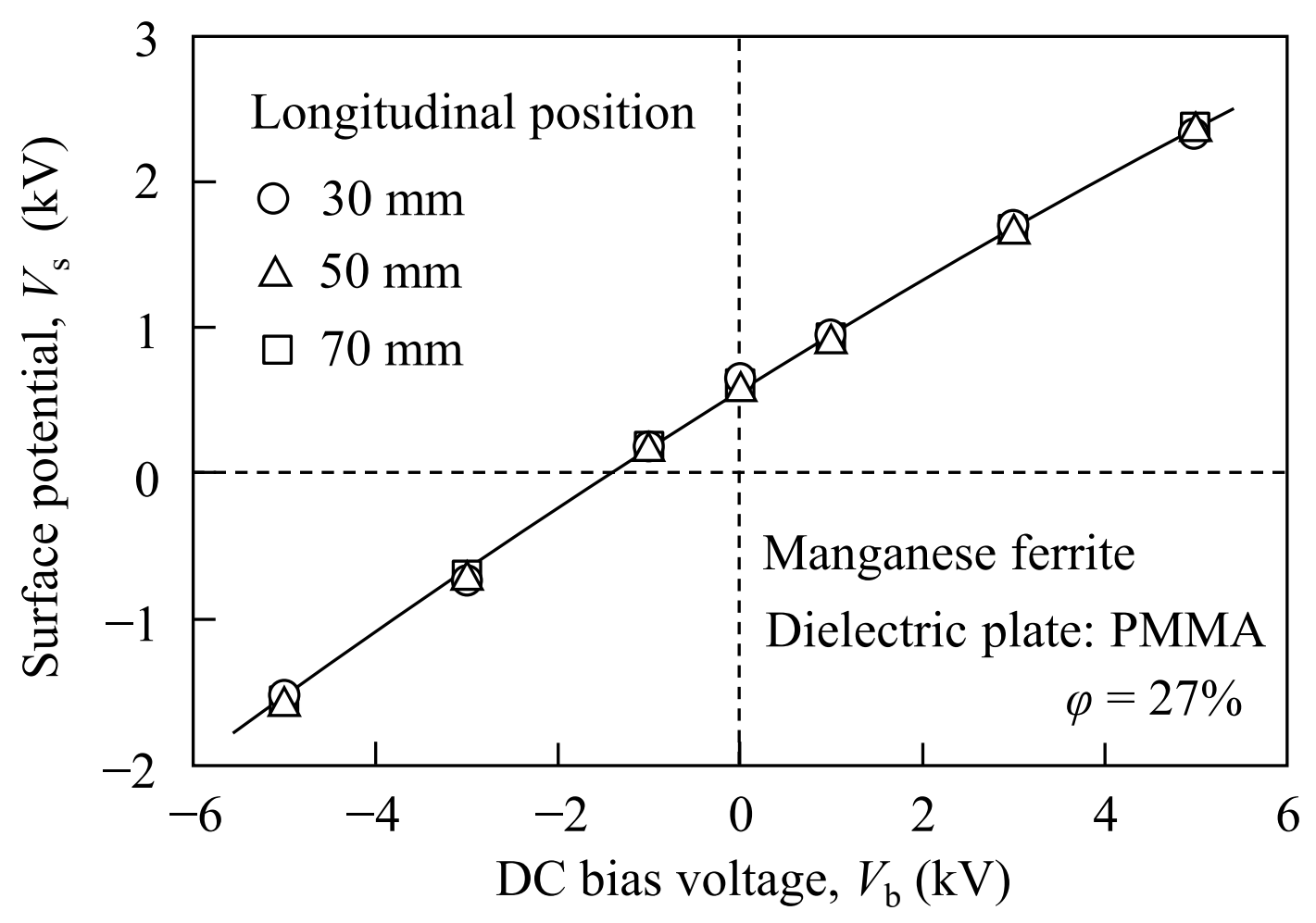

Fig. 19. Relationship between surface potential of the dielectric plate and DC bias voltage applied to the electrode in the APPJ nozzle. 


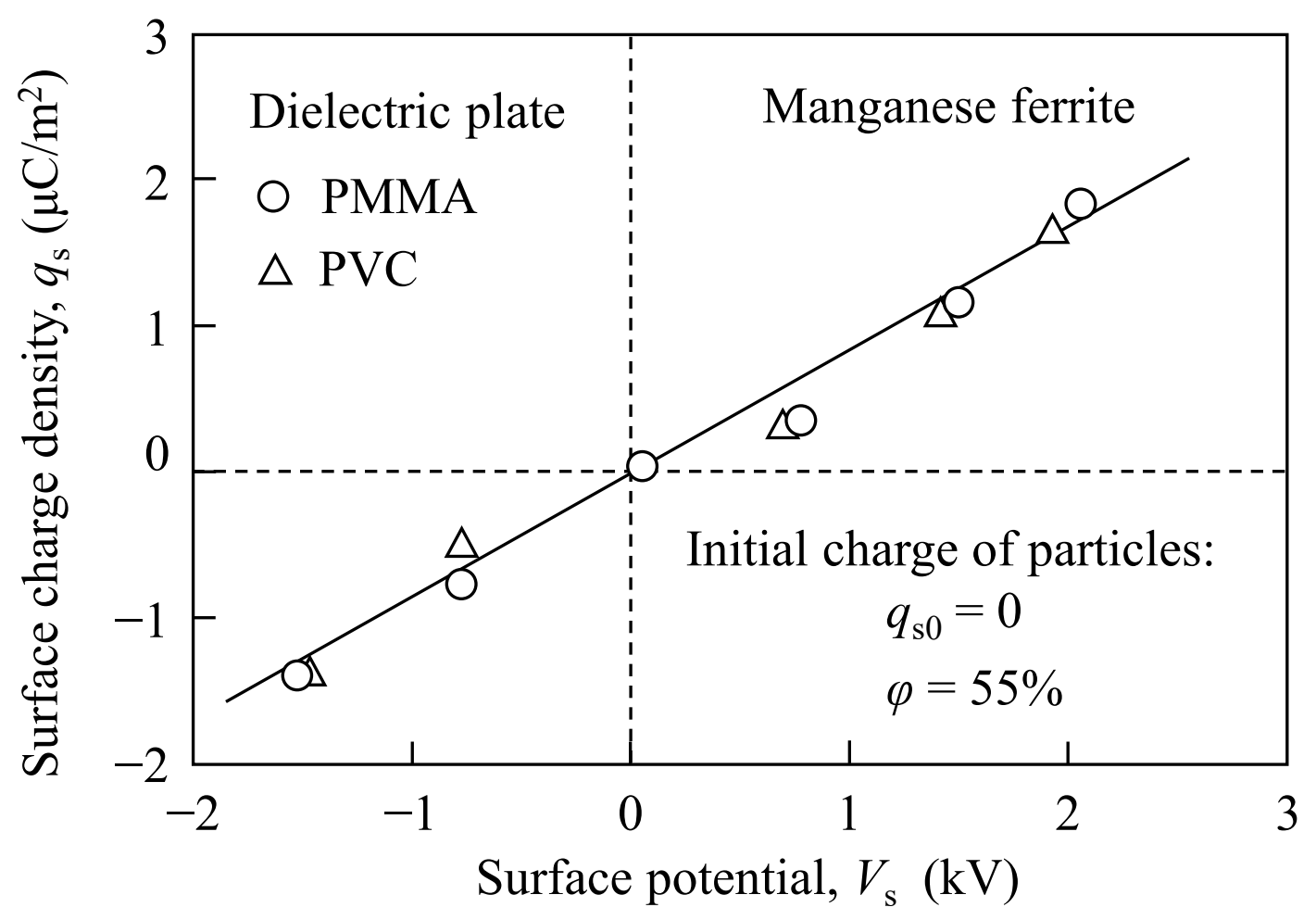

Fig. 20. Relationship between the surface charge densities of particles and surface potential of the dielectric plate. 